\title{
What's in a Network? Infrastructures of Mutual Aid for Digital Platform Workers during COVID-19
}

\author{
RIDA QADRI, Massachusetts Institute of Technology, USA
}

\begin{abstract}
This paper examines the role played by informal mutual aid networks in mediating precarity for gig workers in Jakarta during COVID-19. Using an original survey of 350 mobility platform drivers conducted in May 2020 and a pre-pandemic set of semi-structured interviews with driver communities, I find that mutual aid dispersed through associative, informal labor networks became an essential infrastructure of support for drivers during the pandemic. Most drivers in Jakarta were able to mobilize pre-existing labor networks for extensive material and emotional support. However, results indicate this support was not universally accessible: the pre-pandemic structures of a driver's community and the driver's own participation within the community correlated with the magnitude of community support a driver reported receiving. By putting CSCW literature in conversation with broader literature on informal urbanism, this paper shows how informal labor networks and mutual aid can be a transformative, even outside of formal union structures. By analyzing the forms and limits of these networks this paper also carries lessons in how to build solidarity amongst distributed workforces. At the same time, this study highlights the role of local socio-economic context in shaping gig worker experiences of the pandemic. Thus, it points to the need for more contextually driven analysis of both gig worker precarity and what are deemed effective forms of labor solidarity
\end{abstract}

CCS Concepts: • Human-centered computing $\rightarrow$ Empirical studies in HCI

KEYWORDS: labor solidarity, mutual aid, gig work, platform, COVID-19, Jakarta, Global South

ACM Reference format:

Rida Qadri. 2021. What's in a Network? Infrastructures of Mutual Aid for Digital Platform Workers during COVID-19. In Proceedings of the ACM on Human-Computer Interaction, Vol. 5, CSCW2, Article 419 (October 2021), 20 pages, https://doi.org/10.1145/3479563

\section{INTRODUCTION}

Emerging popular and academic conversations have documented the excessive economic, mental and physical vulnerabilities faced by gig workers during the COVID-19 [3,5,6]. As individuals who could afford to do so retreated to their homes, the burden of this withdrawal was pushed on to gig workers, who were already amongst the most precarious of workers. Ride-hail drivers all over the world saw their incomes plummet and their 'businesses' disappear. On the other hand, delivery platform workers saw an exponential increase in orders, but at the risk of exposing themselves to a virus which, especially in the earlier months, was not well-understood [12].

News stories coming out of a city like Jakarta, however, depicted a slightly different reality: instead of looking to the state or the platform, workers were relying on community support.

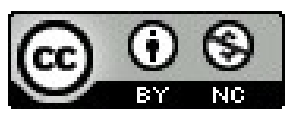

This work is licensed under a Creative Commons Attribution-NonCommercial International 4.0 License.

(C) 2021 Copyright held by the owner/author(s).

2573-0142/2021/10-ART419. https://doi.org/10.1145/3479563

PACM on Human-Computer Interaction, Vol. 5, No. CSCW2, Article 419, Publication date: October 2021. 
Amidst COVID related lockdowns the city's digitized, 'online' motorbike-taxi drivers (called 'ojol') working for mobility-app companies, Grab and GoJek, were reported as providing significant support to each other: from raising assistance for unemployed workers to fumigating neighborhoods [46]. Mutual aid has already been extensively covered in major western news outlets as a panacea for the precarity wrought by the pandemic, [41,47]. Community networks have also been documented by HCI scholarship as a source of occupational support for gig workers [2,20,20,24,25]. These 'practices of democratically-informed mutual aid' [11] though have always been an essential part of precarious work in many countries of the Global South[26,38,39]. Mutual aid is thus, not a new solution nor limited to platform work.

However, evaluating these sources of support becomes particularly important in an employment context with significant barriers to formal unionization, and a legal status that allows platform and state to shirk their responsibilities to the workers[7]. What does the case of Jakarta then suggest about the role informal community networks can play in mediating the material and emotional precarity experienced by platform workers, especially during a crisis like COVID-19 which threatens workers' collective livelihoods?

Jakarta makes for a particularly important case study because its experience with gig work contravenes scholarly concerns over atomized workers and low levels of solidarity within digitally-mediated gig work. Instead, Jakarta is home to hundreds of intricately organized, platform driver associative networks focused on extensive mutual aid, with purposive investment in rituals of solidarity[33]. Most significantly, unlike the mostly online gig worker networks studied in literature, these networks have extensive in-person meeting components through physical spaces called basecamps[33]. These communities have been geared up and institutionally structured to mediate the everyday risks that come with work on a mobility platform: together they have mitigated threats of traffic accidents, lack of employment benefits, and violence from conventional transportation workers. At the same time, they successfully created bonds outside their work, furnishing drivers with robust ties of friendship and care which are not just confined to a small community but are spread across the city amongst thousands of drivers. However, the COVID-19 crisis was one which uniquely challenged drivers. As Jakarta went into lockdown in April, public spaces and offices shut down en-masse, there were less ride-hail orders and certain parts of the city (like commercial downtown areas) fell quiet. An additional blow came when the government announced a ban on motorbike taxi rides in interest of social distancing, so drivers could now only provide food orders. In this context, this paper asks:

RQ1: What forms of support did Jakarta's platform labor solidarity networks provide drivers during the pandemic and to what extent did they fill gaps left by the state and platform?

RQ2: To what extent did pre-pandemic structures of association and community shape the dispersal and experience of support during the pandemic?

To answer these questions, this paper uses two sets of data: 1) an ethnographic study of 30 ojol communities in Jakarta conducted between January 2019-January 2020 and 2) an online survey of 350 ojol in Jakarta between April and May 2020. Combining survey results with pre-pandemic interviews and observations this paper finds that in the midst of inordinate risk pushed on to workers by platform companies, informal labor networks became an essential, albeit limited, infrastructure of support for gig workers. Most drivers in Jakarta were able to mobilize the existing "infrastructures of mutual aid" [23] they had set up pre-pandemic for informational, occupational and emotional support. Survey findings also suggest this support was not universally 
accessible: there was significant differentiation in support drivers reported receiving based on their pre-pandemic participation in their labor network communities.

These findings deepen arguments made by HCI and CSCW scholars studying digital workers' collectives through four contributions. First, this paper shows how mutual aid through highly organized platform labor networks and deep relationships of solidarity even outside of formal union structures can mediate material and emotional precarity of digital work. So far HCI and CSCW scholarship has considered informational and occupational support gained through online networks of gig workers. However, Jakarta's digital platform drivers expand the imagined form and usefulness of these networks. This study documents these rich and varied roles informal networks take on, reminding us that these networks are in fact an essential scaffolding of life in the Global South[14,39].

Second, given the difficulty in creating traditional unions within gig work, this paper's takes on the task of sketching out the effectiveness of this alternative form of worker solidarity. In evaluating these formations of mutual aid and associative labor networks for their transformative promises and limitations, this study expands existing conceptions of digital labor solidarity so as to create a playbook of organizing models gig workers can leverage.

Third, the case of Jakarta becomes a prism to investigate the range of digital labor experiences that can emerge from particular contexts during a historic crisis like COVID-19. This paper shows how outcomes of platform work are refracted by existing forms of market organization and sociopolitical practices, using the 'shock' of COVID-19. Not all gig workers across the globe can be placed in the same category of precarity and crisis, nor do they mediate risk in the same way. It follows calls in HCI literature to study more diverse geographies of technologically- mediated work $[10,48]$ showcasing opportunities for learning from the South to the North.

Lastly, this study's disaggregation of various components of community networks, allows us to consider the social, material and technological intersections of community building. Such an exercise would enrichen our ability to build solidarity amongst distributed workforces.

The rest of the paper is structured in four parts. First, I unpack literature on community networks within gig work. Then I give a brief overview of Jakarta's digital labor formations. Third, I introduce my data collection strategies and methods, upon which the empirics of this paper are based. Fourth, I share survey and interview results on how effective mutual aid formations were for drivers in Jakarta. Lastly, I discuss the implications of these results for theories and practice of gig worker solidarity and collectivization.

\section{RELATED WORK}

\subsection{Informal Labor Networks in Gig Work}

Precarity of gig workers is by now well documented. Locked out as they are of most formal social support safety nets and employer benefits $[4,35]$ they are particularly vulnerable to the risky working conditions and unstable income streams of platform work [51]. Their legal position is also tenuous which results in significant power asymmetries between them and the platform company [23,36]. CSCW literature has, in this context, found extensive evidence of gig workers creating what Gray et al.[17] call "non-unionised networks of mutual help and support". Literature focuses on how online forums are used to create 'communities of support' [20] where workers can gain extensive informational and emotional support. Despite not having any formal, hierarchical obligations, through these personal networks of trust drivers help each other by sharing work tips, socialize new members and aiding with small tasks [37]. Uber Drivers specifically have been seen 
to use these forms to resolve safety and operational challenges[1,24] and to make sense of algorithms [28]. These forums also act as spaces of emotional relief where workers can 'rant' to their peers, gain advice and moral support[20,25].

These collaborations, alliances and networks of trust embedded in gig work and platforms can be considered infrastructural for platform work[16,22,37]. There is, however, little understanding of exactly what role these networks can play (and how effectively) for digital gig workers beyond the two functions literature has mostly focused on: smoothing out work operations through occupational advice and allowing workers to leverage their networks for formal protests. Empirical evaluation of social networks and grass roots organizing for precarious workers outside digital platforms has shown a rich array of roles played by informal associative networks. Peck and Theodore [32], for example, have documented how informal networks developed out of labor associations formed in worker centers can have positive change on work conditions and wages even outside a traditional union structure. Labor scholarship has also considered how the deployment of mutual aid allows fostering of greater unity, allowing workers to consider more than just workplace conditions as a basis for solidarity[31,50]. Writing about street vendors in New York, Duneier[13] makes apparent how non-kinship based networks within informal work are essential even beyond economic sustenance. He argues that this "group life' is where precarious workers 'on the street' can find a sense of identity and dignity. HCI literature can also benefit from unpacking further why these networks are chosen by workers. Mutual aid networks are often used in the Global south and under-resourced settings to fill the vacuum of formal support [21]. Reciprocal relationships for material support as essential to the survival of precarious workers especially in the Global South where other institutions fail [26,39].

When examining such networks, CSCW scholarship has exclusively focused on online relationships, with empirical cases revolving around study of online forums or social media activity. Even as offline communities of digital labor are studied they are ephemeral and unstructured outcroppings of the online interactions[20]. Further research into the interface between offline and online spaces for community building is essential as debate continues as to the role of online vs offline spaces in aiding the development of a robust solidarity for spatially atomized gig workers. Past HCI research on community building has found shared physical spaces important for bolstering social capital [9] and trust [21]. In traditional literature on labor solidarity also a lack of in-person meeting is considered a pernicious barrier to organizing. Emerging literature though has found evidence of digital labor movements using social media sites to develop nascent solidarity and organizing movements that have been effective in creating positive change in workplace conditions[30,49]. Jakarta's ojol networks thus provide an opportunity to measure the implications regular in-person meetings could have in distribution of community resources.

Community networks though, have also been documented to develop a considerable dark side. Labor networks often magnify existing forms of differentiation and segmentation is documented in the economic sociology literature. Granovetter's [15] work for instance, found those who searched for jobs through informal networks to be doing better than those without. Other studies have controlled for gender segregation in networks, which they have found to reinforce occupational segmentation in the labor market[19]. In fact, some have stated how relying on a community "with its elements of group cohesion and insularity, reciprocity, and collective engagement, is perhaps uniquely well-suited to producing exclusion"[44]. Some studies in CSCW have shown preliminary work on how access to worker community resources can be limited by socio-economic and gender variables[20,24]. However, these have not so far systematically 
investigated the ways in which labor collectives can replicate existing inequities. Considering the patterns of exclusion that could be embedded within community networks is an important consideration, especially during crises like COVID-19.

\section{JAKARTA'S DRIVER NETWORKS}

Jakarta's platform labor networks-- with their robust in-person meeting component, immersed in a culture of extensive mutual aid and underpinned by investment in strong occupational identity--provide an excellent empirical case to study the possibilities and limitations of support that come out of mutual aid networks.

Grab and Go-Jek, the two main platforms in Jakarta, started digital operations in 2014. Starting in approximately 2016, online drivers (ojol) began forming informal support communities ('komunitas') to navigate digital work. By 2020, these digital labor komunitas, or communities, had become an all-encompassing source of protection against the unique challenges that come with technologically- mediated employment. Anecdotal estimates by drivers and platform company officers place the number of these communities at around 1500-2000 across Jakarta with each community having anywhere from 5-100 members. They boast a complex network of hierarchical, structured, spatially- rooted networks of mutual aid and emotional support. These networks also feature two components which have been considered essential for developing enduring solidarity within literature on labor organizing: a collective sense of identity and in-person meeting.

Unlike ephemeral community networks which form and disperse for short term help, drivers in Jakarta have displayed a purposive investment in solidarity and rituals. Each 'community' of ojol having a quirky name, an emblem with a logo, multiple WhatsApp groups for communication and constantly use the language of brotherhood and kinship to describe their bonds. All these aspects cultivate a collective image and promote group cohesion [33] allowing drivers to imagine themselves as a collective force. The development of such an identity is considered a necessary if not sufficient condition in creating worker mobilization and common purpose [8].

In Jakarta, ojol interface between both online and offline spaces. While participating in robust networks of WhatsApp groups, Jakarta's ojol also sit under fluttering fluorescent banners of their respective community, stamping their presence on the urban landscape through their 'basecamps'. These basecamps are permanent in-person meeting spaces that drivers brand as their own, ranging from DIY shelters to just a sidewalk spot $<$ see figure $1>$. These become spaces to rest, socialize and be mentored while also charging your phone, as you wait for your next order. The ties developed in-person are solidified on the WhatsApp groups and vice-versa.

These unique features the labor networks have developed are a direct outcropping of the conditions of the pre-digitization mobility market in Jakarta. Unlike the digitization of taxi services in most of the western world, Grab and Go-Jek were intervening in a mode of informal transport that has for decades been indispensable for mobility in the gridlocked city: the motorbike taxi. The informality of the existing unregulated motorbike taxi market meant its drivers were already developing a myriad of strategies to survive and even thrive under conditions of possible precarity [39]. Particularly, much like their digital successors, offline drivers used to form communities around their motorcycle taxi ranks (pangkalans) which furnished both social and economic protection. Internally, the pangkalans organized insurance pools, provided a space of rest and socializing. Each pangkalan controlled the area around it, and only drivers from that pangkalan could pick up passengers in their zone so a 'market' was guaranteed to each group[38]. The centrality of these pangkalans to the business of traditional motorbike taxi drivers gave them the name ojek pangkalan (or opang for short). Given the informality and ground-up forms of 
urbanism popular in Jakarta, motorbike taxi drivers were always able to claim 'stations' around the city.

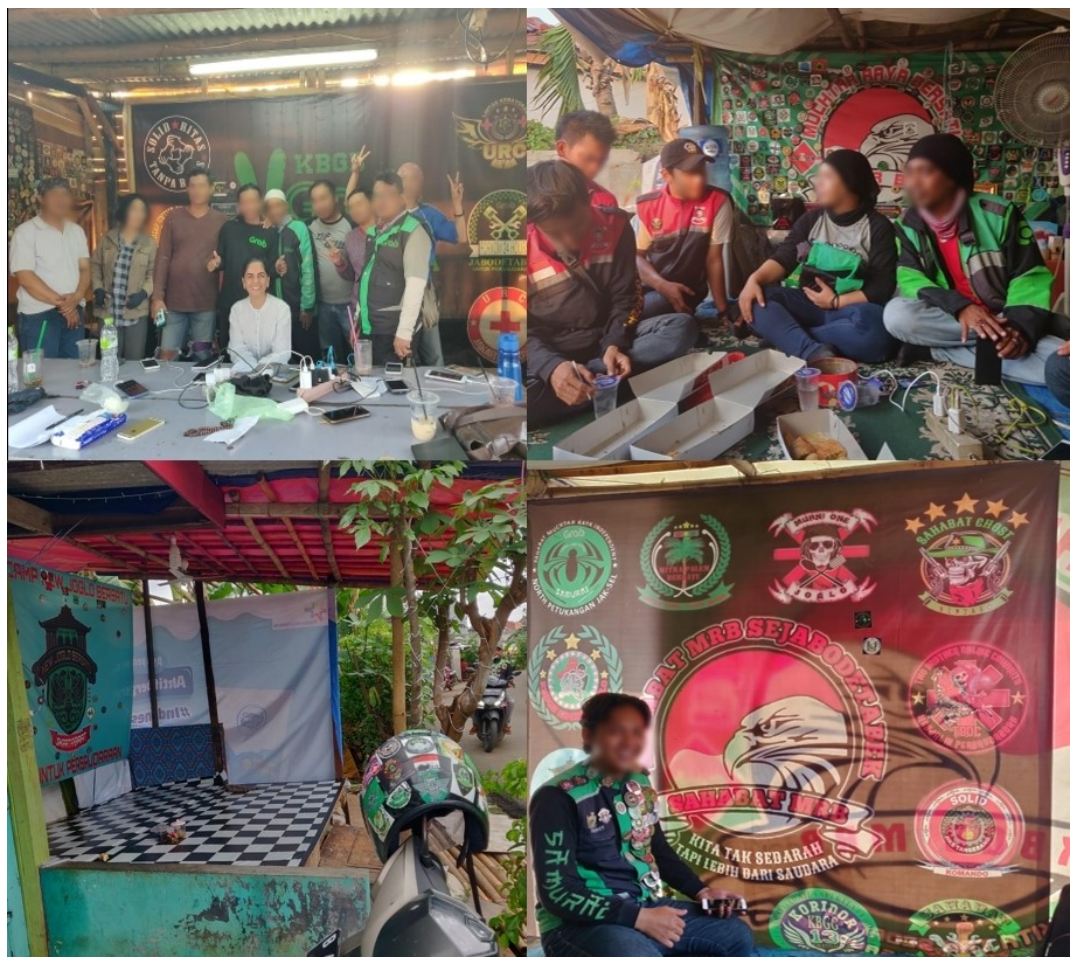

Fig. 1. Various basecamps of driver communities in Jakarta

With the advent of mobility platforms, the traditional ojek industry slowly dwindled and motorbike taxi drivers flocked to the new mobility platforms. Anecdotal estimates from the ridehail companies state anywhere up to $50 \%$ of the 4 million motorbike taxi drivers for the companies were previously informal motorbike taxi drivers[27]. Within the digital market then, older forms of association and socio-spatial practices continued giving the digital motorbike taxi komunitas a distinct form.

Digital labor relationships in large part also reflect Jakarta's norm of creating informal networks of association, kinship and solidarity and deploying collective mutual aid or what Leitner and Sheppard call 'urban commoning' [29]. These practices range from resource sharing within informal neighborhoods[45] to creating informal institutions around grass-root organizing [18]. Simone in his work, expands the role played by these relationships of mutual reciprocity forged within precarious conditions contending the 'economy of generosity' behind the 'social infrastructure' is what keeps urban life within Jakarta going[39]. To what extent these networks also kept life going during the pandemic is to be seen.

\section{DATA COLLECTION}

This paper uses what Mario Small [40] calls a 'mixed data-collection' strategy, drawing on two studies: 1) an online survey of 350 drivers conducted during the pandemic and 2) pre-pandemic interviews and ethnographic observations of 30 driver communities in Jakarta which informed the questions and hypotheses of the eventual survey. 


\subsection{Interviews and observations}

From 2019-2020, I undertook ethnographic fieldwork with mobility platform drivers in Jakarta studying the social relationships and community bonds drivers were immersed in as they labored under the shadow of the platform. Over the span of two fieldwork visits, I conducted face-to-face semi- structured interviews with 30 driver communities. Each interview was conducted at a community's 'basecamp', where I met anywhere from 5-30 drivers; some members of the specific community I was interviewing, others members of different communities visiting their friends. To supplement this data, I also interviewed 10 drivers who were not part of any community, colloquially called 'single fighters'.

The interview questions focused on excavating the specific community's history such as reasons for its formation, understanding its rules and interactions with other communities. Drivers present were also asked for reasons they joined the communities and what benefit they gained from being part of this community. These interviews furnished a deeper understanding of the architectures of solidarity developed by drivers in Jakarta, their practices of mutual aid as well as how these labor formations related to the existing socio-political dynamics of the city [33].

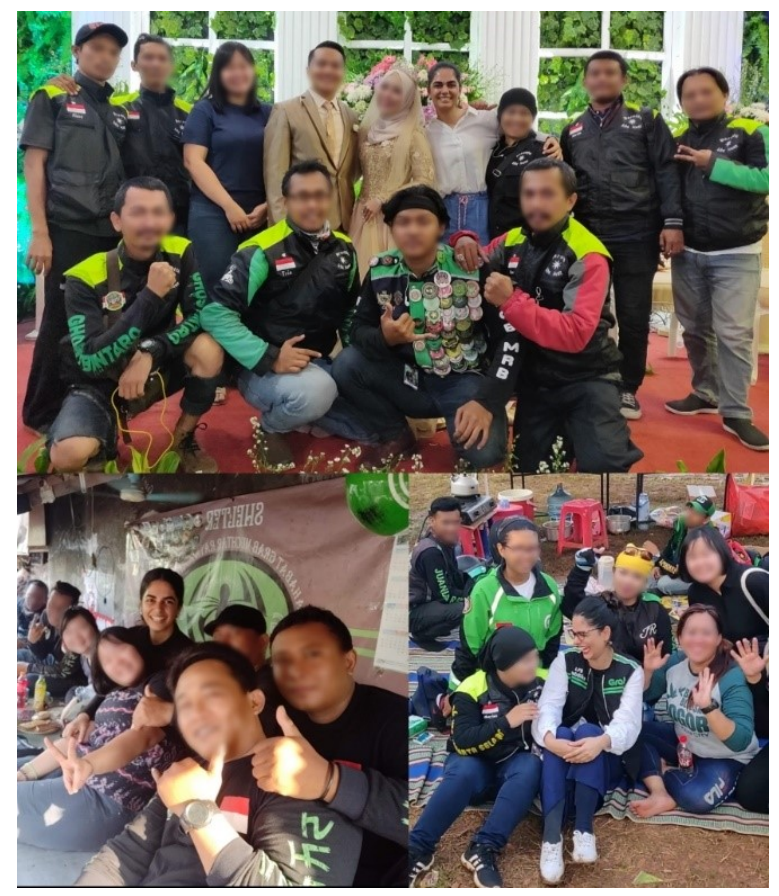

Fig. 2. Varied spaces of interviews and observations

All interviews were conducted in Indonesian, audio-recorded and transcribed. Each initial interview with a community officially lasted an hour, but at each basecamp I spent approximately 3-4 hours talking to drivers, observing their interactions and having conversations outside the interview setting. Through each meeting, we were introduced to other communities, or given invitations to community events like anniversary celebrations or 'family weekends'.

A snowball sampling strategy was used to recruit interview participants. Given the sensitive nature of information revealed and the time I was asking them for, having trust of interview 
participants was key. I thus recruited 3 local RAs to help me with my research, one of them being the daughter of a Gojek driver was able to provide access to driver networks. The close-knit nature of driver communities and frequent visits of drivers from other communities, meant at each interview we were able to expand our network of interviewees.

At some communities having senior drivers (by age or years of experience) present meant junior drivers would speak less. At others, there was a more equitable distribution of opportunities to express individual views. While interviewing in a community setting introduced potential bias, whereby some voices were silenced, it also allowed me to observe the community relationships I was most interested in studying. Due to the focus on the 'collective' in the interviews, individual demographic information was not recorded for the interviewees.

\subsection{Survey}

As I returned from my fieldwork trip in February 2020, whisperings of a global pandemic had begun. Over the next 2 months, as the world locked down, the precarity of gig workers and their role as essential, frontline workers, garnered international attention. In my private conversations with drivers in Jakarta, I saw drivers scrambling to make ends meet, protect their health but also even amidst this precarity, organize charity drives for their fellow drivers. The robust mutual aid networks I had witnessed were now being tested by a global scale crisis, and in April 2020 I decided to do a survey of the drivers to understand both their experiences of the pandemic and the extent of their reliance on community networks as opposed to more formal sources of support.

Digital surveys have often been used to study experiences of platform-mediated work given the physical dislocations of the workforce making traditional in-person surveys difficult. During COVID-19 such surveys have also become particularly important within researcher's repertoire of tools as in-person interviews and travel becoming nearly impossible. Wide use of digital communication by platform drivers in Jakarta makes digital platforms an appropriate means to reach out to the ojol population. Thus, unlike in other contexts, the sample is not biased towards just a small digitally savvy subset of the population.

Survey questions were influenced by my knowledge of the context, the inner workings and priorities of the communities. Such an approach was successfully used by Gray et al. [17] in their pioneering work on digital labor experiences whereby they used ethnographic data to build hypotheses that the survey could be used to test out at a scale difficult with in-depth interviews. My qualitative fieldwork had helped me understand the types of social relationships leveraged within Jakarta's platform labor networks. It was these existing relationships and understandings of the context which allowed me to quickly design and implement a digital survey of drivers as the COVID lockdowns began. I was also able to use the dense connections drivers have developed through WhatsApp groups, to distribute my survey. Access to these networks meant I was able to gather 350 responses within 5-6 hours.

Respondents were offered $\$ 7$ compensation for a completed survey, which was transferred directly to their GoJek or Grab driver account. This step ensured only verified drivers completed the survey. This survey was designed in Indonesian using Qualtrics and subsequently distributed using WhatsApp and Twitter. As with other digital surveys where the full population is not known, a convenience sample was used with a snowballing sampling strategy. Key informants identified through fieldwork and interviews were given the link requesting distribution through their community WhatsApp groups. One community with a twitter presence was also asked to post the link on their Twitter feed. While I couldn't control where the survey went, all the people I had met and interviewed through my fieldwork did fill out the survey. Using my own networks 
which I had developed during the interviews was an attempt to ensure the survey would be circulated amongst the communities I had interviewed, to have some commensuration between the survey and interview samples.

The survey had 4 sections. The first section asked drivers about their mode of work and engagement with community pre-pandemic with questions on the area drivers look for orders in, whether their community has a basecamp or a WhatsApp group or not, whether they considered themselves an active part of a community or not. The second section investigated changes in work experiences after COVID-19 e.g. impact on income, strategies or areas drivers worked in, how they kept themselves safe etc. The third section asked about forms of support sought and received from various parties. Lastly, demographic information was collected such as age, gender and the company worked for. Each section had open ended questions at the end, asking drivers if there was anything else they wished to share about their experiences.

Median response time was 15 minutes and 350 respondents completed the full survey. There was a balance in the sample regarding the companies worked for with $53.7 \%$ of the sample working for Grab and $46.3 \%$ for Gojek, reflecting the claim that Jakarta's market is a duopoly. Median age of respondents was 32 with 60 being the maximum age. $91 \%$ of the sample was male and $9 \%$ was female, which is unsurprising given the male dominance of the motorbike taxi market. However, in my interviews, while fewer in number, women were an active part of the basecamps. A majority of drivers received the survey through their community WhatsApp groups with $62 \%$ of the sample receiving the survey through their community WhatsApp Group. $13 \%$ of the respondents received the link through a personal WhatsApp message from another driver and 25\% found it through Twitter. This is perhaps also why we have a high proportion of Active members in the sample with $62 \%$ of the sample reporting themselves as an active member of a driver community.

\subsection{Analysis}

During my qualitative fieldwork, I had used an inductive coding technique to analyze the interviews, whereby after each interview I noted down relevant analytical themes that had emerged or been confirmed in the process. The observations and side conversations became part of this meta-analysis and helped inform the directions of the conversation in the interview and the interpretative framework used for the analysis for the interview data. Preliminary themes emergent from the interviews included the forms of mutual aid drivers furnished each other, structures of the various communities, obligations and entitlements of community participation and differentiation within experiences of community aid across the driver population. Codes related to these parts of the study were used to interpret and analyze the survey data.

This prior knowledge became particularly important as I tested for differences in experiences of community support across the ojol respondents. Based on my fieldwork, I hypothesized four variables to be relevant for self-reported reliance on community support: pre-existing levels of participation in the community, the driver's community having an in-person meeting component, the company a driver worked for and primary area served. Age and gender were also added to the models as controls.

- Participation: This was a categorical measure using answers in response to the question: "What best describes your relationship with your driver community: Active member, inactive member, not part of any community/single fighter." While participation level was self-reported, during fieldwork I observed a relatively consistent criteria of what 
makes an active member: engagement in conversations on WhatsApp groups, spending at least a few hours a week with other members of the community, and participation in activities of mutual aid for the wider community. $62 \%$ of the sample self-selected as active participants.

- In-person meeting: This was a binary measure of whether the driver's community had a basecamp or not. Both in interviews and in literature on labor organizing in person meeting was considered an essential component of developing labor solidarity and a collective identity. It is important to note though that a significant part of Jakarta's platform labor network organization is organized through an interface of online and offline modes of communication. In the survey $73 \%$ drivers who were part of a community reported having access to a basecamp that they visited regularly. $50 \%$ of the drivers used both WhatsApp and basecamp to communicate with drivers, 35\% used only WhatsApp to communicate with each other and $8 \%$ used only basecamps.

- Area: A binary measure for whether the driver worked in 'central areas' or not. In the interviews, drivers during fieldwork had reported differences present between communities who set up camp in centre of the city and those in what the referred to the 'outskirts': i.e. non-core, suburban areas of the city. Drivers in the centre were thought to be more focused on work while those in the outskirts on 'socializing'.

- Company: A binary measure for whether the driver worked for GoJek or Grab. There was a perception amongst some drivers that GoJek drivers were less likely to create communities for a variety of reasons. The anecdotal explanation provided was that Gojek drivers were less likely to congregate in public spaces due to security architecture of the application, which allowed drivers to create fake GPS traces, and get orders while as drivers called it, 'hiding away'. Being away from public spaces reduced chances of meeting other drivers or needing the kind of help drivers in Grab communities relied on.

Area and Company did not return significant results for bi-variate tests of correlation with community support, but both active and in-person had significant effect at the $95 \%$ level on levels of community support accessed. I then used an ordinal logistic regression model to assess the effect of participation (active/inactive) and in-person meeting (basecamp/no basecamp) on likelihood of driver accessing higher levels of community support measured ordinally at 4 levels. Age and Gender did not show any significant impact on community aid received (Kruskal-Wallis test, $\mathrm{p}>0.1$ ) and thus would not bias results of how and where community aid was experienced. This model is discussed further in the results section.

\section{RESULTS}

\subsection{Platform labor networks as a source of support during COVID-19}

Survey results indicate that the pre-pandemic 'infrastructure of mutual aid' [22] created in Jakarta through ojol communities continued operation during the pandemic (Figure 3). $70 \%$ of survey respondents reported receiving 'moderate support' or 'a lot of support' from these driver communities through the pandemic. On the other end of the spectrum the only $29 \%$ reported similar levels of support from the government and $15 \%$ from the platform. It is interesting to note how close reported support from the communities was to that received from kinship ties such friends and family (74\% of survey respondents reported receiving 'moderate support' or 'a lot of support' from friends and family).

This finding is in line with my observations of solidaristic mobilization and mutual aid structures during pre-COVID fieldwork. Unlike empirical settings of existing studies on digital 
labor, where workers rely on each other only for small favors, digital platform drivers in Jakarta had already created an extensive and efficient structure of mutual aid to respond to everyday crises of work which they could leverage in the face of larger crises. Pre-pandemic drivers reported a history of undertaking large scale collective action such as citywide negotiations with traditional motorbike groups, providing 'ambulance escort services' when an ojol or a family member needs medical attention and collecting charity for natural disasters. In the start of 2020 in fact, with historic floods in Indonesia, multiple communities participated in a nationwide fundraising effort for at least a month. Underlying these actions is significant investment in a shared ojol identity; Salam Satu Aspal "Greetings from the Single Road" is a cry much heard in driver circles. The feeling of solidarity ran so deep that drivers have reported actively sacrificing potential income when engaging in mutual aid activities by rejecting matched orders or simply turning their apps off. Given the socio-economic standing of drivers who rely on daily wages for their income, this income hit from even skipping one order is significant.

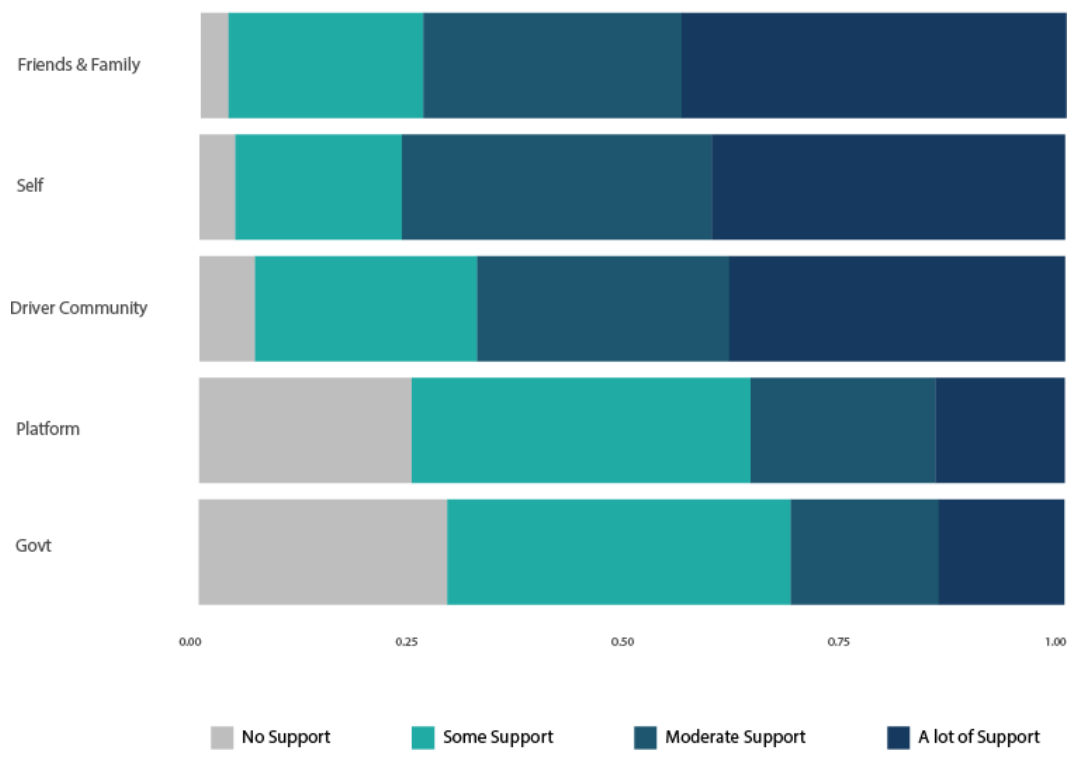

Fig.3. Reported support from each actor in response to question: 'How much support have the following parties provided during COVID-19"

Drivers also rely on a diversity of support sources outside the community: primarily family/friends and themselves. This latter source of support also is not as individualistic as it first appears since in interviews drivers talking about doing things themselves meant they patching together informal sources of support outside formal institutions. While literature often separates kinship ties from occupational ties, survey results show friends/family and driver communities being similar in drivers' imagined constellation of support. Interview data explains why. Prepandemic descriptions of the types of ties forged in these solidarity networks routinely used language of kinship. Drivers were ' brothers on the road' and reasons for taking care of each other were straightforward: "Kita tidak sedarah tapi kita lebih dari keluarga" (we may not be [the same] blood but we are more than family). Another common refrain was, Panggilan Hatti, or 'a calling of the soul'. 
To understand the relative levels of obligations drivers placed on the different possible sources of support, the survey asked respondents how much support they thought each party should provide them during COVID-19 (Figure 4). The resultant distribution of entitlements from the community were surprising: only $37 \%$ of respondents felt driver communities had high obligations to provide support. In contrast, $88 \%$ felt the government had a similarly high obligation of support and $77 \%$ felt so about platform companies. In free-text responses in the survey, a few drivers explained that they did not want to expect anything from their fellow drivers because of how significantly they were all struggling.

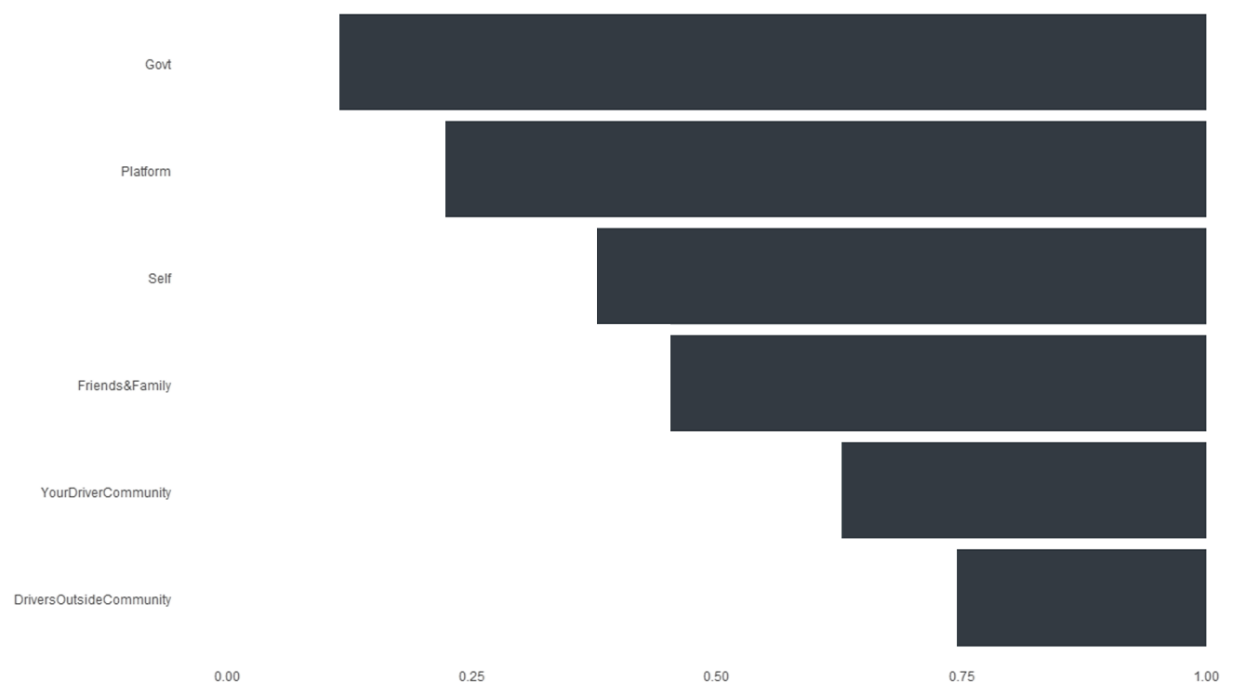

Fig.4. Percentage of respondents who selected 'should give support' for each named actor in response to 'Should the following parties provide support during COVID19'

Such minimal expectations from driver communities were a departure from narratives recorded during fieldwork where drivers explained mutual aid to be a creed, not a choice. There was constant refrain of how high obligations that came as being part of a community drove a lot of the mobilization. In pre-pandemic interviews, drivers repeatedly took pride in 'doing things through the community' and all interviews touched upon responding to state/platform absence through reliance on community. According to one driver interviewed pre-pandemic, Grab as a Singaporean company, was blindsided by drivers 'Indonesian specific' relationships: "If we have problems we run to our friends and basecamp, not to Grab". This observation was borne out by how little Grab and Go-Jek featured in driver conversations when discussing crises. Many drivers reported not even taking up Go-Jek and Grab's opt-in insurance offers due to expense of bureaucratic processes, instead relying on their community provided insurance. In the face of a bigger crisis than what they have imagined before, it seems those entitlements have flipped.

\subsection{Forms of support sought through communities}

Rates of reported material support from communities rivaled (and slightly exceeded) that provided by the platform (figure 5). Even in a time of significant financial upheaval for most drivers, communities were able to mobilize for material support through the infrastructures they 
had in place. One source of funding for this mutual-aid is the 'aresan' (monthly membership dues communities used to collect pre-pandemic), which earlier was used as an insurance mechanism for community members.

A particularly significant finding from the survey is the extent drivers in Jakarta seem to be relying on their communities for emotional support. Approximately $70 \%$ of respondents reported driver communities as a source of emotional support, a feature not focused on in scholarship. In answers to open-ended questions in the survey asking drivers to explain the type of support communities provided, respondents described how they relied on their communities to "help them have faith", to not give up, to cheer them on in what one driver described as 'never-ending emotional help'. Given the elevated stress experienced during this pandemic, the mental health benefit of driver communities cannot be dismissed.

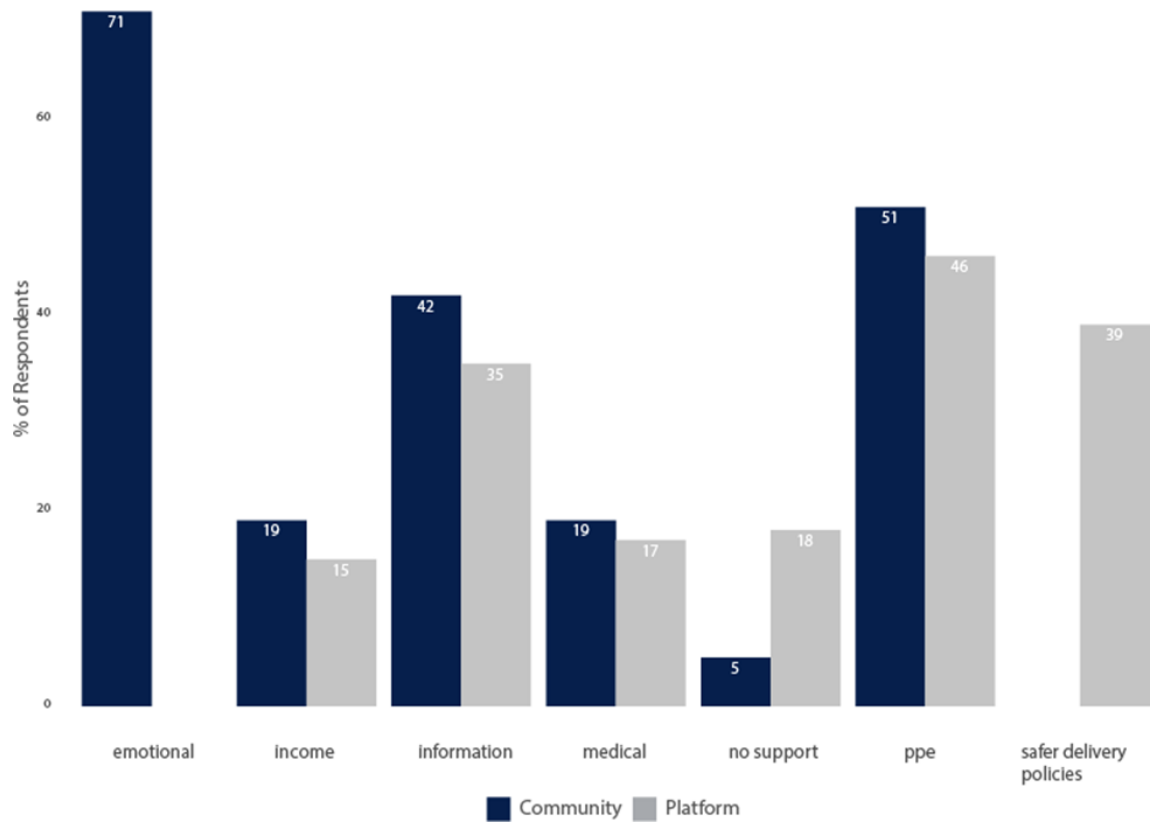

Fig.4. Percentage of respondents who stated receiving the named form of support in response to question [Did you seek the following sources of support from <community/platform>] * ppe is personal protective equipment

Such high reports of emotional support are likely a result of pre-pandemic investment in social ties, 'hanging out,' participating in and organizing community events. With frequent social interactions both online and at basecamps, the ojol have bulwarked against the isolation digital work can bring but also able to create ties of friendship which are expressed through emotive language of brotherhood and kinship . Drivers often used emotive phrases in describing their fellow drivers, referring to their basecamps as a 'second home.'

\subsection{Community deployed mutual aid is not universally accessible}


When looking at the survey respondents as one undifferentiated whole, community support seems like a panacea for the precarity of gig work. However, labor networks can amplify differentiation and take on exclusionary tendencies within the same market.

Two variables returned significant results for a nonparametric Wilcoxon rank-sum test for impacting the level of community support accessed $(\mathrm{p}<0.01)$ : participation and in-person meeting. Both had overlap with each other in the sample (table 1). A majority of the sample was active and had a basecamp.

Table 1. Overlap in sample between being participation and in person meeting

\begin{tabular}{ccc}
\hline & $\begin{array}{c}\text { No } \\
\text { Basecamp }\end{array}$ & Basecamp \\
\hline Not Active & $8 \%$ & $9 \%$ \\
Active & $8 \%$ & $74 \%$ \\
\hline
\end{tabular}

As a measure of robustness, I also tested the covariates impact on levels of support garnered from friends and family and self, but found no significant effect, indicating support experiences only differ for community-centered aid. Equation 1 below estimates the likelihood of drivers accessing higher levels of community support based on participation (active/inactive) and inperson meeting (basecamp/no basecamp).

$$
\operatorname{logit}[P(Y \leq j)]=a_{j}-\sum \beta_{i} X_{i}
$$

Where $\mathrm{j}$ is the level of community support 1-4 $(1=$ 'No Support ; $2=$ 'Some Support'; $3=$ 'Moderate Support'; $4=$ 'A Lot of Support')

i refers to 5 independent variables ( 1 = 'active' $(0$ or 1$) ; 2=$ 'in-person' $(0$ or 1$)$; $3=$ 'age'; $4=$ 'area' $(0$ or 1$)$; $5=$ gender $(0$ or 1$)$

When considering participation separately, Model 1 shows a driver being an 'active' member of the community increased their odds of accessing higher levels of community support by $2.4 \mathrm{x}$ (Table 2). Similarly, drivers in communities with basecamps were twice as likely to access higher levels of support than drivers without a basecamp (Table 2; Model 2). However, in Model 3 when both covariates are added (Table 2), it is clear there was substantial shared variance. The in-person covariate parameter value dropped to 1.4. There is thus clear overlap between those who have inperson meetings and those who are active-in-person meetings alone are not a sufficient condition to guarantee mutual aid. During interviews, drivers hinted at this relationship when they mentioned physical basecamps and meeting requirements as distractions from the 'job'-and thus only indulged in by 'community focused' drivers. The causality of this relationship though is unclear. Do in-person meetings lead to drivers becoming more community- focused or do only community focused drivers have in-person meeting? The relationship between 'active ' drivers and presence of a 'basecamp' will be investigated in future work, post-COVID. $61 \%$ of drivers stated their time at basecamps had decreased due to the pandemic. This provides an opportunity to investigate the impact of reduced in-person meeting in the longevity of ties.

This result also helps put into context the first set of findings on levels of community support accessed by the sample. Given the high number of active participants in our sample, they may be inflating reported support communities provided. However, this caveat does not take away from the role communities are playing for active members, even if their support for inactive members is diminished. 
Table 2. Impact of participation on likelihood of driver accessing higher levels of community support (Level 1-4) ${ }^{* * *} \mathrm{p}<0.01^{* *} \mathrm{p}<0.05^{*} \mathrm{p}<0.1$

\begin{tabular}{ccccccc}
\hline & \multicolumn{2}{c}{ Model 1 } & \multicolumn{2}{c}{ Model 2 } & \multicolumn{2}{c}{ Model 3 } \\
\hline & Odds Ratio & SE & Odds Ratio & SE & Odds Ratio & SE \\
\hline Participation & 2.4 & 0.22 & & & 2.35 & 0.4 \\
In-Person & & & 0.36 & 1.4 & 0.38 \\
& & & & & \\
Age & Not sig & & Not sig & & Not sig \\
Company & Not sig & Not sig & Not sig \\
Area & Not sig & & Not sig & Not sig \\
\hline
\end{tabular}

As suggested by these findings, community-driven mutual aid in Jakarta is not universally accessible. Whether this suggests deliberate exclusions, or personal tendencies of inactive members choosing not to access community networks is difficult to say. However, it is clear that pre-pandemic reciprocity and participation did mediate driver's experiences of support. In a context where community aid becomes one of the largest sources of material and emotional support, such 'un- democratic' basis for support can perpetuate vulnerability. So where inactive or non-community members are left to figure things out themselves, drivers in community networks benefit from stable reliable information networks, shelters, mentoring and crisis response.

While all the problems communities help with are not insurmountable, they do require investing time and resources into their resolution. One driver I interviewed explained "if you're not part of a community why would senior drivers help you? Maybe if they're your friend'." Drivers interviewed pre-pandemic, who were not part of a community or were inactive reported that while they mostly tried to sort out problems themselves, or rely on personal familial networks. This withdrawal from aid was mostly reported to be self-policed or logistical i.e. drivers either felt uncomfortable asking for help from any driver communities because they did not feel entitled to it or if they were not part of a particular community did not have access to the network of WhatsApp groups and basecamps where help could be offered and received. On the flip side, being part of a community also has significant unpaid labor and financial costs attached to it, given the associated activities you sign up to be part of after gaining membership of a community. These include mutual aid tasks, socializing, being active on WhatsApp groups, attending functions and events. In fact, some drivers join communities only after evaluating their 'socializing' and meeting requirements. Reasons for not wanting extensive requirements ranged from drivers wanting to spend time with their family, not wanting to be distracted from work, and not wanting the burden of constantly having to help others.

\section{DISCUSSION}

The results discussed in this paper have three significant implications for HCI scholarship: 1) Evaluating effectiveness of community networks in dispersing support for gig workers ; 2) Considering the transformative power of mutual aid networks when compared to unions ;3) Assessing the importance of in-person meetings for building relationships in distributed work settings. 


\subsection{Informal Networks and Distribution of Support}

In Jakarta, mutual aid deployed through labor networks and built around a culture of kinship was able to mediate to some extent COVID-19 related precarity and emotional vulnerability. Gig workers, when unable to get support from the state or platforms, were not lone wolves facing the crisis completely on their own. These mutual aid networks of drivers demonstrated significant resilience in the face of a crisis that threatened drivers' collective livelihood, still active even as obligation was lower in a pandemic. In addition to family and friends, it was these worker networks that kept workers floating; forms of reciprocal relationships that are a hallmark of precarious work in the Global South (and Global North e.g. see the work of Dean Spade) [43]

On the other hand, Jakarta's ojol also highlight the exclusions that can be embedded within ground- up informal labor networks. In Jakarta, being an 'active member' in ojol communities usually involves significant unpaid labor of attending weekly or monthly meetings, volunteering for community activities/mutual aid and socializing either online or offline. Drivers report skipping orders to continue their obligations of participation or because 'they were having too much fun.' Expecting this level of unpaid labor from drivers for support might also discriminate against those who are the most vulnerable. Community networks of digital labor can then become spaces of exclusion similar to those within non-digitized work. It can also be argued that these collectives, by centering mutual aid, allow the bare minimum functioning of workers while letting the state and platform off the hook. That drivers have to take on the burden to create dignified work systems for themselves is by no means fair. Research especially on motorbike taxis does take this tension into account, e.g. when Sopranzetti remarks that motorbike taxi work in Bangkok is "emancipation and oppression all the way down"[42]. It is these limitations of digital labor collectives that make it even more important to undertake a clear-eyed, contextually sensitive sociological analysis which acknowledges their potentials, but does not romanticize their survival tactics.

We thus require nuanced, contextual, and granular analysis of what community networks can offer workers across a spectrum of socio-economic realities. If workers can benefit from support outside the state and platform, how can these efforts be made least burdensome for workers themselves? The study also raises question of whether already marginalized populations are less likely to benefit from gig worker collectives. If yes, any collective formed would have to actively mitigate these inequities.

\subsection{Transformative Potential of Mutual Aid}

Mutual aid has both become increasingly central in popular and academic conversations postpandemic but also at the same time dismissed as unenduring by frameworks trained to seek evidence of formal organizing In fact the initial wave of literature on platform labor, while considering the relational elements of such solidarity labor networks, saw limited transformative potential in networks of digital workers, framed as little more than occupational 'random acts of kindness' [37]. However, most evaluation of these mutual aid networks has been done with an eye towards comparing them with more formal organizational structures like unions, or by searching for evidence of legal action or protest

Informal collectives, as seen in Jakarta, can accelerate the preconditions to developing worker power: creating collective interests, shared identities and channels of communications. Rizzo and Atzeni[34], writing about precarious workers' agency and collectivization efforts, argue that when debates about worker solidarity "revolve around the trade union as the exclusive organizational and institutional form of workers' representation, [it misses] the formation processes of workers' 
collective organization in the case of unorganized informal and precarious workers. If we only focus on evidence of protests or strikes, we close out the possibility of investigating the myriad of functions informal labor networks can fulfill for a digital worker. This paper joins emerging work on platform work in considering the importance of labor networks and 'communities of beyond just occupational support and even without becoming sites for collective bargaining.

The latent power drivers in Jakarta have developed in their informal collectives have also given drivers the belief that they can negotiate with, bargain with and engage with the platform companies. The scale achieved by worker networks through the connections between communities, and investment in collective identity now makes them a force in Jakarta's urban landscape. The possibilities of the political action these communities wield, even if unleveraged translated during COVID-19 as priority in aid dispensation towards the drivers by both the platform and state, a far cry from the US. In fact, while in the US the state and the platform have played a round of passing the buck for who is responsible for the welfare of the platform worker numerous driver support initiatives were quickly implemented in Indonesia post-COVID. Platform companies were forced, in response to mounting community collective aid efforts, to provide gig workers with grocery vouchers, income support, and support with installing protective partitions in their vehicles. The state specifically targeted aid delivery to the ojol post-lockdowns, with President Jokowi himself distributing food staples [46]. The political visibility and organization of drivers in Jakarta thus has helped make them a potential power broker. Even before the pandemic, drivers reported routinely being able to access upper management of the platform companies. On their part companies routinely engage with leaders of the larger driver communities, as they would with union leadership.

The case of Jakarta's labor organization thus shows that digital labor action, even outside unions and protests, can help drivers in responding to and withstanding economic shock. Platform workers' organization thus should not only be judged by its capacity to formally bargain with the state or capital. Mounting challenges to unionization of gig workers and globalization of digital platform work make it essential that we consider seriously appropriate forms of worker organization that can exist in a myriad of regulatory and socio-political contexts.

There may not be a one- size-fits-all model for gig worker organizing and thus attention should be given to how labor organizing works within a diversity of contexts. For instance, Jakarta's platform labor networks were quick to mobilize during the pandemic because pre-pandemic drivers had already participated in labor-intensive aid dispensation beyond just small occupational tasks. This type of solidarity was made possible because of the specific form of labor associational relationships in Jakarta, which in turn were impacted by the labor market context within which digital platforms in Jakarta entered. With nascent organizing efforts evident in the gig economy, the time is nigh to start considering what a global playbook of digital labor relationships would look like.

\subsection{Building solidarity in distributed workforces}

In the world of remote work, investigating the role of in-person communication for building relationships in distributed workforces continues to be important. Much like with remote work, one of the hurdles in gig worker solidarity is considered to be employee fragmentation and sociospatial atomization. Ojol of Jakarta creatively overcame this barrier by deftly interfacing between online and offline interactions. The use of basecamps, a permanent physical meeting space, community events, and WhatsApp groups shows how technologically mediated offline community networks can create enduring ties of solidarity. Basecamps also showcase the 
possibility of 'shopfloors', considered indispensable to building worker collective interests, existing in gig work as well. This case though, also shows how physical interaction alone is not a guarantor of robust community ties. With new online social technologies like WhatsApp allowing for more dynamic conversations, in person meetings may only be important for sustaining existing bonds. There is also clear promise shown for the use of communication technologies that support flexible forms of communication in group setting to further cement ties. Future work can investigate further how online technologies interfacing with offline spaces can produce richer forms of labor association.

\section{CONCLUSION}

As crises like COVID-19 decimate existing forms of infrastructure, community networks are becoming an important part of the repertoire of survival strategies of vulnerable gig workers. Through studying and investigating the diverse forms of effective solidarity that can be constructed within precarious platform mediated work, we get closer to understanding how digital labor can navigate autonomy, dependence and participation in an employment context like gig work where community networks are increasingly key to survival. The ojol-driven solidarity networks of Jakarta teach us that there is a contextually-driven role of mutual aid groups within gig work, given they are underpinned by a broad conception of solidarity, there is investment in both in-person and online interaction and a conscious effort is made to overcome the exclusions that can be embedded within such networks of association.

\section{ACKNOWLEDGMENTS}

This research was partially funded by MIT's Industrial Performance Center and Work of the Future Taskforce. I would like to thank Melita Terisa, Novi Ade and Diah Paramita for their help with interviewing and surveys. Madeleine Daepp, Asmaa ElGammal, Isadora Cruxen, Yonah Freemark, Emilia Simison and all the reviewers who provided invaluable comments and feedback.

\section{REFERENCES}

[1] Abdullah Almaatouq, Peter Krafft, Yarrow Dunham, David G. Rand, and Alex Pentland. 2020. Turkers of the World Unite: Multilevel In-Group Bias Among Crowdworkers on Amazon Mechanical Turk. Social Psychological and Personality Science 11, 2 (March 2020), 151-159. DOI:https://doi.org/10.1177/1948550619837002

[2] Mashael Yousef Almoqbel and Donghee Yvette Wohn. 2019. Individual and Collaborative Behaviors of Rideshare Drivers in Protecting their Safety. Proc. ACM Hum.-Comput. Interact. 3, CSCW (November 2019), 217:1-217:21. DOI:https://doi.org/10.1145/3359319

[3] Juan Carlos Alvarez de la Vega, John Rooksby, and Marta E. Cecchinato. 2020. The Gig Economy in Times of COVID-19: Designing for Gig Workers' Needs. (2020), 9.

[4] Mohammad Amir Anwar and Mark Graham. 2020. Hidden transcripts of the gig economy: labour agency and the new art of resistance among African gig workers. Environ Plan A 52, 7 (October 2020), 1269-1291. DOI:https://doi.org/10.1177/0308518X19894584

[5] Bénédicte Apouey, Alexandra Roulet, Isabelle Solal, and Mark Stabile. 2020. Gig Workers during the COVID-19 Crisis in France: Financial Precarity and Mental Well-Being. J Urban Health (September 2020). DOI:https://doi.org/10.1007/s11524-020-00480-4

[6] Lindsey D Cameron and Jordan Nye Fekete. Heros or Schmucks?: Implications of the Hero Narrative for Gig Workers During the CoVid-19 Pandemic. 18

[7] Lindsey D Cameron and Alex Rosenblat. 2020. Gig Work Used to Be a Recession-Proof Safety Net. Not Anymore. Fast Company. Retrieved from https://medium.com/fast-company/gig-work-used-to-be-a-recession-proof-safety-netnot-anymore-e74a6d9ed854

[8] Callum Cant and Jamie Woodcock. 2020. Fast Food Shutdown: From disorganisation to action in the service sector. Capital \& Class 44, 4 (December 2020), 513-521. DOI:https://doi.org/10.1177/0309816820906357 
[9] Tawanna R. Dillahunt and Jennifer Mankoff. 2014. Understanding factors of successful engagement around energy consumption between and among households. In Proceedings of the 17th ACM conference on Computer supported cooperative work \& social computing, ACM, Baltimore Maryland USA, $1246-1257$. DOI:https://doi.org/10.1145/2531602.2531626

[10] Tawanna R. Dillahunt, Xinyi Wang, Earnest Wheeler, Hao Fei Cheng, Brent Hecht, and Haiyi Zhu. 2017. The Sharing Economy in Computing: A Systematic Literature Review. Proc. ACM Hum.-Comput. Interact. 1, CSCW (December 2017), 1-26. DOI:https://doi.org/10.1145/3134673

[11] Veena Dubal. 2019. Gig Worker Organizing for Solidarity Unions. LPE Project. Retrieved January 16, 2021 from https://peproject.org/blog/gig-worker-organizing-for-solidarity-unions/

[12] Veena Dubal and Meredith Whittaker. 2020. Uber drivers are being forced to choose between risking Covid-19 or starvation. the Guardian. Retrieved October $26, \quad 2020$ from http://www.theguardian.com/technology/2020/mar/25/uber-lyft-gig-economy-coronavirus

[13] Mitchell Duneier. 2001. Sidewalk (1st paperback edition ed.). Farrar, Straus and Giroux, New York.

[14] James Ferguson. 2015. Give a Man a Fish: Reflections on the New Politics of Distribution. Duke University Press. DOI:https://doi.org/10.1215/9780822375524

[15] Mark S. Granovetter. 1995. Getting a job: a study of contacts and careers (2nd ed ed.). University of Chicago Press, Chicago.

[16] Mary L. Gray and Siddharth Suri. 2019. Ghost work: how to stop Silicon Valley from building a new global underclass. Houghton Mifflin Harcourt, Boston.

[17] Mary L Gray, Siddharth Suri, Syed Shoaib Ali, and Deepti Kulkarni. 2016. The Crowd is a Collaborative Network. In Proceedings of the 19th ACM Conference on Computer-Supported Cooperative Work \& Social Computing - CSCW '16, ACM Press, San Francisco, California, USA, 134-147. DOI:https://doi.org/10.1145/2818048.2819942

[18] Patrick Guinness. 2009. Kampung, Islam and state in urban Java. University of Hawaii Press, Honolulu.

[19] Susan Hanson and Geraldine Pratt. 1991. Job Search and the Occupational Segregation of Women. Annals of the Association of American Geographers 81, 2 (June 1991), 229-253. DOI:https://doi.org/10.1111/j.14678306.1991.tb01688.x

[20] Maya Holikatti, Shagun Jhaver, and Neha Kumar. 2019. Learning to Airbnb by Engaging in Online Communities of Practice. Proc. ACM Hum.-Comput. Interact. 3, CSCW (November 2019), 1-19. DOI:https://doi.org/10.1145/3359330

[21] Julie Hui, Nefer Ra Barber, Wendy Casey, Suzanne Cleage, Danny C. Dolley, Frances Worthy, Kentaro Toyama, and Tawanna R. Dillahunt. 2020. Community Collectives: Low-tech Social Support for Digitally-Engaged Entrepreneurship. In Proceedings of the 2020 CHI Conference on Human Factors in Computing Systems, ACM, Honolulu HI USA, 1-15. DOI:https://doi.org/10.1145/3313831.3376363

[22] Lilly C. Irani and M. Six Silberman. 2013. Turkopticon: interrupting worker invisibility in amazon mechanical turk. In Proceedings of the SIGCHI Conference on Human Factors in Computing Systems - CHI '13, ACM Press, Paris, France, 611. DOI:https://doi.org/10.1145/2470654.2470742

[23] Lilly C. Irani and M. Six Silberman. 2013. Turkopticon: interrupting worker invisibility in amazon mechanical turk. In Proceedings of the SIGCHI Conference on Human Factors in Computing Systems (CHI '13), Association for Computing Machinery, New York, NY, USA, 611-620. DOI:https://doi.org/10.1145/2470654.2470742

[24] Vaishnav Kameswaran, Lindsey Cameron, and Tawanna R. Dillahunt. 2018. Support for Social and Cultural Capital Development in Real-time Ridesharing Services. In Proceedings of the 2018 CHI Conference on Human Factors in Computing Systems, ACM, Montreal QC Canada, 1-12. DOI:https://doi.org/10.1145/3173574.3173916

[25] Neha Kumar, Nassim Jafarinaimi, and Mehrab Bin Morshed. 2018. Uber in Bangladesh: The Tangled Web of Mobility and Justice. Proc. ACM Hum.-Comput. Interact. 2, CSCW (November 2018), 1-21. DOI:https://doi.org/10.1145/3274367

[26] Abidin Kusno. 2019. Provisional Notes on Semi-Urbanization. In Routledge handbook of urbanization in Southeast Asia, Rita Padawangi (ed.). Routledge, Taylor \& Francis Group, London; New York.

[27] Doreen Lee. 2018. How ojek became gojek: disruptive technologies and the infrastructure of urban citizenship in Indonesia.

[28] Min Kyung Lee, Daniel Kusbit, Evan Metsky, and Laura Dabbish. 2015. Working with Machines: The Impact of Algorithmic and Data-Driven Management on Human Workers. In Proceedings of the 33rd Annual ACM Conference on Human Factors in Computing Systems, ACM, Seoul Republic of Korea, 1603-1612. DOI:https://doi.org/10.1145/2702123.2702548

[29] Helga Leitner and Eric Sheppard. 2018. From Kampungs to Condos? Contested accumulations through displacement in Jakarta. Environ Plan A 50, 2 (March 2018), 437-456. DOI:https://doi.org/10.1177/0308518X17709279

[30] Michael David Maffie. 2020. The Role of Digital Communities in Organizing Gig Workers. Ind Relat 59, 1 (January 2020), 123-149. DOI:https://doi.org/10.1111/irel.12251

[31] Bruce Nissen and Paul Jarley. 2005. Unions as Social Capital: Renewal through a Return to the Logic of Mutual Aid? Labor Studies Journal 29, 4 (January 2005), 1-26. DOI:https://doi.org/10.1177/0160449X0502900401 
[32] Jamie Peck and Nik Theodore. 2012. Politicizing Contingent Work: Countering Neoliberal Labor Market Regulation... from the Bottom Up? South Atlantic Quarterly 111, 4 (October 2012), 741-761. DOI:https://doi.org/10.1215/003828761724165

[33] Rida Qadri. 2020. Algorithmized but not Atomized? How Digital Platforms Engender New Forms of Worker Solidarity in Jakarta. In Proceedings of the AAAI/ACM Conference on AI, Ethics, and Society, ACM, New York NY USA, 144-144. DOI:https://doi.org/10.1145/3375627.3375816

[34] Matteo Rizzo and Maurizio Atzeni. 2020. Workers' Power in Resisting Precarity: Comparing Transport Workers in Buenos Aires and Dar es Salaam. Work, Employment and Society (July 2020), 095001702092824. DOI:https://doi.org/10.1177/0950017020928248

[35] Alex Rosenblat. 2018. Uberland: how algorithms are rewriting the rules of work. University of California Press, Oakland, California.

[36] Alex Rosenblat and Luke Stark. 2016. Algorithmic Labor and Information Asymmetries: A Case Study of Uber's Drivers. International Journal of Communication 10, (2016), 27.

[37] Niloufar Salehi, Lilly C. Irani, Michael S. Bernstein, Ali Alkhatib, Eva Ogbe, Kristy Milland, and Clickhappier. 2015. We Are Dynamo: Overcoming Stalling and Friction in Collective Action for Crowd Workers. In Proceedings of the 33rd Annual ACM Conference on Human Factors in Computing Systems- CHI '15, ACM Press, Seoul, Republic of Korea, 1621-1630. DOI:https://doi.org/10.1145/2702123.2702508

[38] A. M. Simone. 2014. Jakarta: drawing the city near. University of Minnesota Press, Minneapolis; London.

[39] AbdouMaliq Simone. 2008. The politics of the possible: Making urban life in Phnom Penh. Retrieved October 9, 2020 from https://onlinelibrary.wiley.com/doi/abs/10.1111/j.1467-9493.2008.00328.x

[40] Mario Luis Small. 2011. How to Conduct a Mixed Methods Study: Recent Trends in a Rapidly Growing Literature. Annu. Rev. Sociol. 37, 1 (August 2011), 57-86. DOI:https://doi.org/10.1146/annurev.soc.012809.102657

[41] Rebecca Solnit. 2020. "The way we get through this is together": the rise of mutual aid under coronavirus Coronavirus | The Guardian. the Guardian. Retrieved January 13, 2021 from https://www.theguardian.com/world/2020/may/14/mutual-aid-coronavirus-pandemic-rebecca-solnit

[42] Claudio Sopranzetti. 2017. Owners of the map: motorcycle taxi drivers, mobility, and politics in Bangkok. University of California Press, Oakland, California.

[43] Dean Spade. 2020. Mutual aid: building solidarity during this crisis (and the next). Retrieved March 14, 2021 from https://rbdigital.rbdigital.com

[44] Stephanie M Stern. THE DARK SIDE OF TOWN: THE SOCIAL CAPITAL REVOLUTION IN RESIDENTIAL PROPERTY LAW. 69.

[45] John Sullivan. 1992. Local government and community in Java: an urban case-study. Oxford University Press, Singapore; New York.

[46] Farida Susanty. 2020. What about the others? 'Ojol' relief sparks concerns over aid inequality. The Jakarta Post. Retrieved October 25, 2020 from https://www.thejakartapost.com/news/2020/04/16/what-about-the-others-ojolrelief-sparks-concerns-over-aid-inequality.html

[47] The Economist. 2020. Mutual-aid groups spread in covid-stricken America. The Economist. Retrieved January 13, 2021 from https:/www.economist.com/united-states/2020/12/19/mutual-aid-groups-spread-in-covid-strickenamerica

[48] Jacob Thebault-Spieker, Loren Terveen, and Brent Hecht. 2017. Towards a Geographic Understanding of the Sharing Economy: Systemic Biases in UberX and TaskRabbit. (2017), 42.

[49] Katie J Wells, Kafui Attoh, and Declan Cullen. 2020. "Just-in-Place" labor: Driver organizing in the Uber workplace. Environ Plan A (August 2020), 0308518X20949266. DOI:https://doi.org/10.1177/0308518X20949266

[50] Jane Wills and Melanie Simms. 2004. Building reciprocal community unionism in the UK. Capital \& Class 28,1 (March 2004), 59-84. DOI:https://doi.org/10.1177/030981680408200105

[51] Alex Wood and Vili Lehdonvirta. 2021. Platform Precarity: surviving algorithmic insecurity in the gig economy. Social Science Research Network, Rochester, NY. DOI:https://doi.org/10.2139/ssrn.3795375

Submitted January 2021; revised April 2021; revised July 2021; accepted July 2021. 